\title{
Chronic pulmonary sarcoidosis: relationship between lung lavage cell counts, chest radiograph, and results of standard lung function tests
}

\author{
YH LIN, PL HASLAM, M TURNER-WARWICK \\ From the Department of Thoracic Medicine, Cardiothoracic Institute, London
}

\begin{abstract}
Thirty three consecutive untreated patients with pulmonary sarcoidosis, confirmed histologically or by Kveim test, were investigated to correlate cell counts in bronchoalveolar lavage fluid with clinical features, the chest radiograph, and results of lung function tests. A persistently abnormal radiograph had been observed for one year or more in $26(79 \%)$ and for two years or more in $20(61 \%)$, but only $24 \%$ had dyspnoea. Twenty $(61 \%)$ of 33 patients showed an increased percentage of lymphocytes in bronchoalveolar lavage fluid, although only eight $(24 \%)$ exceeded $28 \%$. A moderate increase of neutrophils, up to $12 \%$, was found in 14 $(42 \%)$. Lymphocyte percentage counts were higher in the group of patients without evidence of radiographic contraction suggesting fibrosis, and this contrasted with higher percentage neutrophil counts in those with contraction. There was also a correlation between the percentages of neutrophils and increasing radiographic profusion scores $(p<0.001)$, suggesting that neutrophils may reflect the severity of the parenchymal legions as well as fibrotic distortion, and an inverse correlation with vital capacity $(p<0.001)$ and transfer factor (TLCO) $(p<0.1>0.05)$. No significant correlation was found between the lymphocyte counts and radiographic profusion scores, vital capacity or TLCO; but it was noted that all eight patients with high lymphocyte counts $(>28 \%)$ had radiographic profusion scores less than 12 . This study shows that, especially in sarcoidosis with more extensive radiographic shadows of long duration, bronchoalveolar lavage neutrophils may be important as well as lymphocytes in clinical assessment of "activity" of disease. These observations are important because they throw doubt on whether the lavage lymphocyte count alone can be used as an indicator of the need to start corticosteroid treatment.
\end{abstract}

There is now general agreement that lymphocytes, especially $\mathrm{T}$ cells, are the most common cell type proportionately increased above the normal range in bronchoalveolar lavage samples from patients with sarcoidosis. ${ }^{1}$ The prevalence of patients showing such an increase and the extent of this increase, however, varies considerably in different reports ${ }^{2-5}$ (table 1). Probably many factors contribute to this variation, including the "activity stage" of disease and its chronicity as well as racial factors.

It has been suggested that the $T$ lymphocyte count in lavage samples reflects the "intensity" of the

Address for reprint requests: Professor M Turner-Warwick, Department of Thoracic Medicine, Cardiothoracic Institute, London SW3 6HP.

Accepted 19 February 1985 alveolitis in sarcoidosis and that treatment policies may be designed on this basis..$^{5}$ If such changes in bronchoalveolar lavage fluid are to be used to dictate treatment policies, it becomes important to document the relationship between lymphocytes and other cells in lavage fluid with the clinical variables, especially in patients with disease of longer duration, in whom treatment decisions often have to be made.

As part of a larger study assessing the value of newer methods of monitoring sarcoidosis before and during treatment, bronchoalveolar lavage has been undertaken in all patients with histologically proved sarcoidosis referred to us. The population considered here is particularly appropriate in the clinical context, because most of the patients were seen by us at a time when the referring centre was considering the need for treatment. Thus the estimated dura501 
Table 1 Reported percentages of bronchoalveolar lavage (BAL) lymphocytes in patients with pulmonary sarcoidosis

\begin{tabular}{|c|c|c|}
\hline & No of cases studied & $\begin{array}{l}\text { \% of BAL } \\
\text { lymphocytes } \\
\text { (mean (SD)) }\end{array}$ \\
\hline $\begin{array}{l}\text { Yeager et al }{ }^{2} \\
\text { Arnoux et al } l^{3} \\
\text { Perrim-Fayolle et al } \\
\text { Crystal et al } \\
\text { Present series* }\end{array}$ & $\begin{array}{r}10 \text { (non-smokers) } \\
4 \text { (smokers) } \\
103 \\
30 \\
45 \\
33\end{array}$ & $\begin{array}{l}19.6(5.2) \\
8.0(2.1) \\
34 \quad(18) \\
39 \text { (range 5-78) } \\
33(6) \\
19.7(2.9) \\
\text { (range } 0.8-66.4)\end{array}$ \\
\hline
\end{tabular}

* Mainly persistent disease.

tion of disease was longer, the patients are older than in many previous reports, and all but four had parenchymal shadowing on the chest radiograph. This report considers a consecutive group of untreated patients with pulmonary sarcoidosis, most of whom had had known disease for over a year, and the relationship between the lavage cell counts, a quantitative and qualitative evaluation of the chest radiographs, and results of standard lung function tests. The relationship of these variables with steroid responsiveness is reported separately.

Table 2 Clinical features of the patients studied

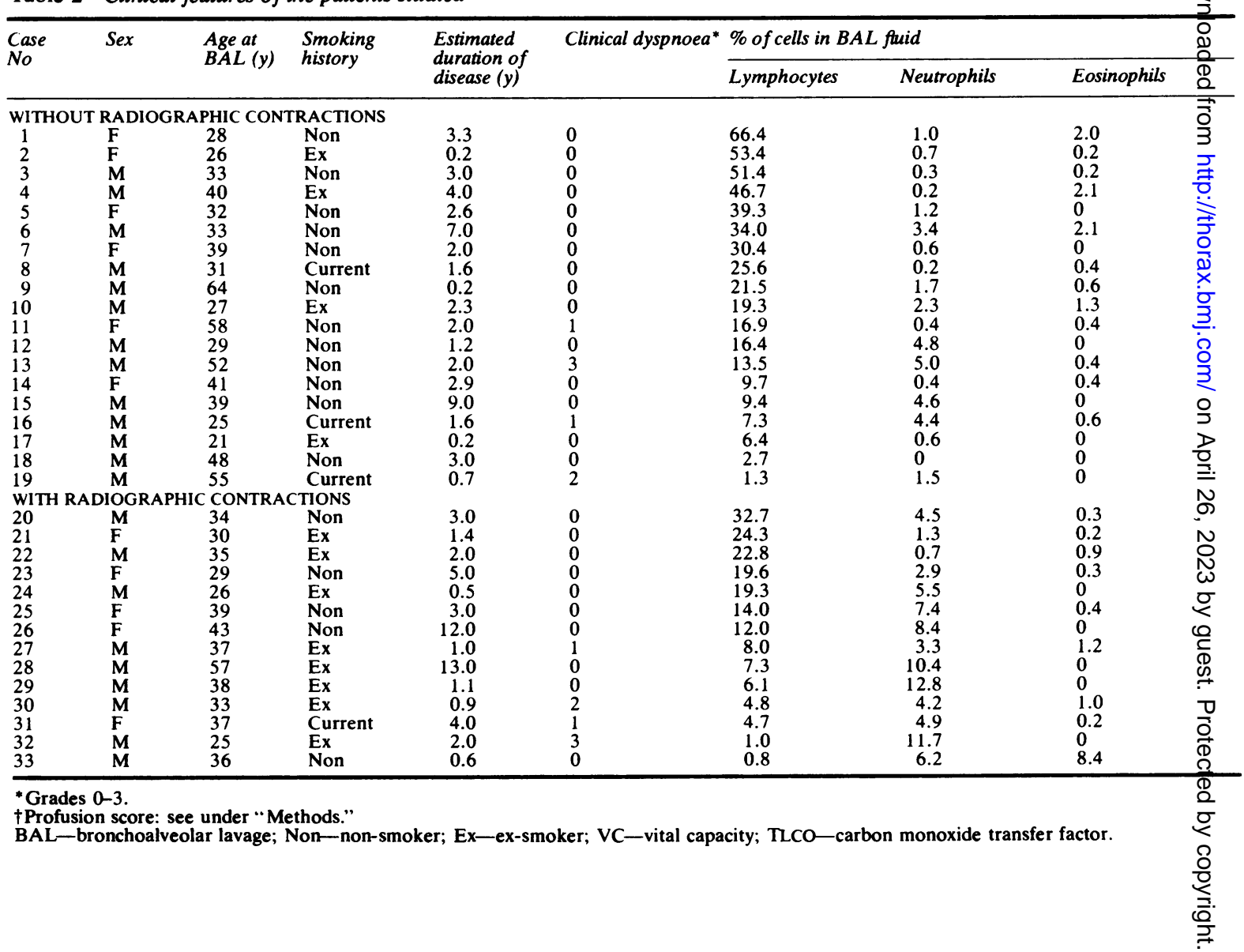

\section{Methods}

\section{PATIENTS}

A total of 43 new patients with pulmonary sarcoidosis was seen during 1977-81. The diagnosis was confirmed by tissue biopsy ( 39 cases) or Kveim test (four cases). Thirty eight patients were untreated at the time of bronchoalveolar lavage but five were already receiving corticosteroid treatment. For various reasons two untreated patients did not have a lung lavage, and in one patient excess mucus in the lavage sample prevented a reliable count. A high count of ciliated and squamous epithelial cells suggested important contamination of the bronchial lumen in two other patients. These five patients have been excluded, and this report analyses the remaining 33 untreated cases (29 confirmed histologically and four by Kveim test).

The clinical features are shown in table 2. There were 22 men and 11 women with a mean (SD) age of $37(10.5)$ with a range of 21-64 years. Twenty four $(73 \%)$ were aged 30 years or more when studied. All but three were caucasian. Four patients were current smokers, 12 ex-smokers, and 17 non- 
smokers. Duration of disease was estimated from the time of the first abnormal chest radiograph, though we recognise that this is likely to be an underestimate of the actual duration of disease. The mean (SD) duration of disease at the time that bronchoalveolar lavage was performed was 2.98 (3.1) years with a range of two months to 13 years. Twenty $(61 \%)$ of the 33 had a duration of disease of two or more years. Only seven patients had had known disease for less than one year; three of these already showed radiographic linear shadows and contraction, making it probable that actual disease was of considerably longer duration. Only one patient in the series had had a duration of less than one year, with hilar node shadows as the only radiographic abnormality.

All chest radiographs were read by a single observer who was experienced in the use of the ILO/UC classification ${ }^{6}$ but unaware of the bronchoalveolar lavage cell counts and results of lung function tests at the time. In this classification the size of small rounded opacities are graded by comparison with standard films as $\mathrm{p}, \mathrm{q}$, and r, and small irregular opacities as $\mathbf{s}, \mathrm{t}$, and $\mathrm{u}$. The classification was modified so that a profusion score was given to each lung separately and a score of $0 / 0-3 / 3$ provided a nine point scale of abnormality for each lung, and thus an 18 point profusion score of abnormality for the whole radiograph. The radiographs were also graded by conventional staging (the term "type" is now preferred), as follows: stage 0 -no apparent abnormality; stage 1-hilar or mediastinal lymphadenopathy, or both, without parenchymal shadows; stage 2-lymphadenopathy with parenchymal shadows; stage 3-parenchymal shadows only. Our correlations of bronchoalveolar lavage cell counts and conventional staging in this group have been reviewed previously. ${ }^{7}$ In addition, the presence of lung contraction with displacement of the fissures or hilar shadows and the presence of linear shadows suggesting fibrosis were recorded. All but four had stage II or III disease and $14(42 \%)$ had evidence of linear radiographic shadows or contraction suggesting "fibrosis"- that is, appearances likely to be irreversible with treatment. A standard four point clinical grading of dyspnoea was used to

\begin{tabular}{|c|c|c|c|c|c|c|c|}
\hline \multicolumn{6}{|c|}{ Chest radiograph } & \multirow{2}{*}{$\begin{array}{l}V C \\
\text { (\% pred) }\end{array}$} & \multirow{2}{*}{$\begin{array}{l}\text { TLCO } \\
\text { (\% pred) }\end{array}$} \\
\hline Staging & Profusion $†$ & Zonet & Typet & Contraction & Linear shadows & & \\
\hline II & 18 & 6 & $r$ & 0 & 0 & 96.1 & 50.7 \\
\hline II & 6 & 6 & $q$ & 0 & 0 & 92.3 & 74.8 \\
\hline II & 8 & 6 & $t$ & 0 & 0 & 101.4 & 88.6 \\
\hline I & 0 & 0 & o & 0 & 0 & 103.3 & 49.1 \\
\hline III & 10 & 6 & $q$ & 0 & 0 & 84.9 & 84.7 \\
\hline II & 12 & 6 & $\mathrm{q}$ & 0 & 0 & 58.5 & 40.2 \\
\hline III & 12 & 6 & $\mathbf{q}$ & 0 & 0 & 96.9 & 59.9 \\
\hline I & 0 & 0 & o & 0 & 0 & 99.9 & 85.2 \\
\hline III & 10 & 4 & $q$ & 0 & 0 & 119.9 & 89.0 \\
\hline II & 6 & 6 & $\mathrm{p}$ & 0 & 0 & 101.3 & 63.7 \\
\hline II & 4 & 3 & s & 0 & 0 & 105.7 & 95.5 \\
\hline I & 0 & 0 & o & 0 & 0 & 87.4 & 79.2 \\
\hline II & 13 & 6 & $\mathbf{u}$ & 0 & 0 & 68.3 & 76.7 \\
\hline III & 3 & 2 & $\mathbf{s}$ & 0 & 0 & 62.3 & 78.6 \\
\hline III & 12 & 5 & $\mathbf{u}$ & \pm & 0 & 107.6 & 84.2 \\
\hline II & 9 & 2 & $\mathrm{t}$ & $\overline{0}$ & 0 & 95.5 & 110.0 \\
\hline I & 0 & 0 & o & 0 & 0 & 93.1 & 86.8 \\
\hline III & 4 & 4 & $q$ & 0 & 0 & 123.8 & 106.7 \\
\hline II & 10 & 6 & $\mathrm{t}$ & 0 & 0 & 76.6 & 28.8 \\
\hline II & 8 & 6 & $q$ & + & + & 89.9 & 83.7 \\
\hline III & 14 & 6 & $\mathrm{r}$ & + & + & 92.5 & 75.8 \\
\hline III & 15 & 5 & $\mathrm{r}$ & + & 0 & 88.0 & 78.9 \\
\hline III & 10 & 4 & $\mathrm{r}$ & + & 0 & 98.0 & 70.5 \\
\hline II & 18 & 6 & $\mathbf{u}$ & + & + & 74.7 & 66.0 \\
\hline III & 16 & 6 & $\mathbf{u}$ & + & + & 57.8 & 52.3 \\
\hline II & 16 & 6 & $\mathbf{u}$ & + & + & 67.3 & 81.4 \\
\hline III & 10 & 5 & $\mathbf{s}$ & + & + & 80.5 & 71.4 \\
\hline III & 14 & 6 & $\mathbf{u}$ & + & + & 50.1 & 21.6 \\
\hline III & 14 & 4 & $\mathbf{u}$ & + & + & 75.4 & 80.4 \\
\hline III & 13 & 6 & u & + & + & 74.7 & 54.0 \\
\hline III & 15 & 5 & $\mathbf{s}$ & + & + & 91.3 & 75.8 \\
\hline II & 18 & 6 & $t / r$ & + & + & 51.0 & 44.3 \\
\hline III & 13 & 5 & $t$ & + & + & 47.1 & 26.7 \\
\hline
\end{tabular}


assess breathlessness. ${ }^{8} 25(76 \%)$ had no dyspnoea and only four (12\%) had dyspnoea of grade 2 or 3 .

\section{LUNG FUNCTION TESTS}

The standard pulmonary function tests undertaken in all patients have been described previously." Static and dynamic lung volumes and the transfer factor for carbon monoxide (TLCO) were measured by standard methods. Only the vital capacity (VC) and TLco are included in the present analysis. Results have been expressed as percentages of values predicted for sex, age, and height for a caucasian population. ${ }^{10}$ Nineteen $(58 \%)$ of our patients had a vital capacity of $85 \%$ of the predicted value or greater; $26(79 \%)$ had a TLCO of less than $85 \%$ of the predicted value.

\section{BRONCHOALVEOLAR LAVAGE}

The technique and equipment used for bronchoalveolar lavage and the analysis of cells have been described previously." The normal upper limit for smokers in our laboratory is $11 \%$ for lavage lymphocytes, $4 \%$ for neutrophils, and $3 \%$ eosinophils. The percentages of lymphocytes obtained by our cytocentrifugation technique have now been validated by fixing bronchoalveolar lavage fluid cells in suspension in glutaraldehyde, pelleting them in agar, embedding them in epon, and counting the cells in $1 \mu \mathrm{m}$ sections (PL Haslam and A Dewar, unpublished observation). Non-smoking normal controls have been reported to show occasionally slightly higher figures for lymphocytes (average $18 \%$ ). ${ }^{12}$

\section{STATISTICS}

Mean values with their standard deviation are quoted where appropriate. Where data are not normally distributed median values are shown and quantitative data correlations tested with a Spearman rank analysis. A Mann-Whitney $U$ test has been used for comparisons of groups.

Table 3 Correlations of bronchoalveolar lavage (BAL) cell counts with chest radiographic profusion score and results of pulmonary function tests in 33 patients

\begin{tabular}{lcl}
\hline & $\begin{array}{c}\text { Correlation } \\
\text { coefficient }(r)\end{array}$ & $p$ \\
\hline BAL lymphocytes and VC & 0.368 & $<0.1>0.05$ \\
BAL neutrophils and VC & -0.651 & $<0.001$ \\
BAL lymphocytes and TLCO & 0.087 & NS \\
BAL neutrophils and TLCO & -0.337 & $<0.1>0.05$ \\
BAL lymphocytes and profusion & -0.175 & NS \\
score & 0.638 & $<0.001$ \\
$\begin{array}{l}\text { BAL neutrophils and profusion } \\
\text { score }\end{array}$ & 0.05 \\
\hline
\end{tabular}

VC-vital capacity; TLCO-carbon monoxide transfer factor; NS-not significant.

\section{Results}

LAVAGE FLUID DIFFERENTIAL CELL COUNTS

Most of the cells in the bronchoalveolar lavage fluid samples were macrophages, but an increased percentage $(>11 \%)$ of lymphocytes was found in 20 $(61 \%)$ of the 33 patients (table 2). The median count was $16.9 \%$ with a range of $0.8-66.4 \%$. Eight ( $24 \%$ ) had lymphocyte counts of $28 \%$ or greater. An increase of neutrophils was found in $14(42 \%)$ patients; the median count was $3.1 \%$ with a range of $0-12.8 \%$. An increase in both lymphocytes and neutrophils was found in six $(18 \%)$ of the patients and a completely normal count in five $(15 \%)$. There was a significant negative correlation between the percentages of lymphocytes and neutrophils $(p<0.01)$ (fig 1). Only one patient (No 33) showed an abnormal eosinophil count.

\section{CORRELATION BETWEEN LAVAGE CELL COUNTS} AND CHEST RADIOGRAPH (table 3)

Although there was no significant correlation between the percentage of lymphocytes and the profusion score of the chest radiograph there was a significant correlation between the percentage of neutrophils and profusion score $(p<0.001$; fig 2$)$, while all eight patients with lymphocyte counts greater than $28 \%$ had radiographic profusion scores of less than 12 (table 2).

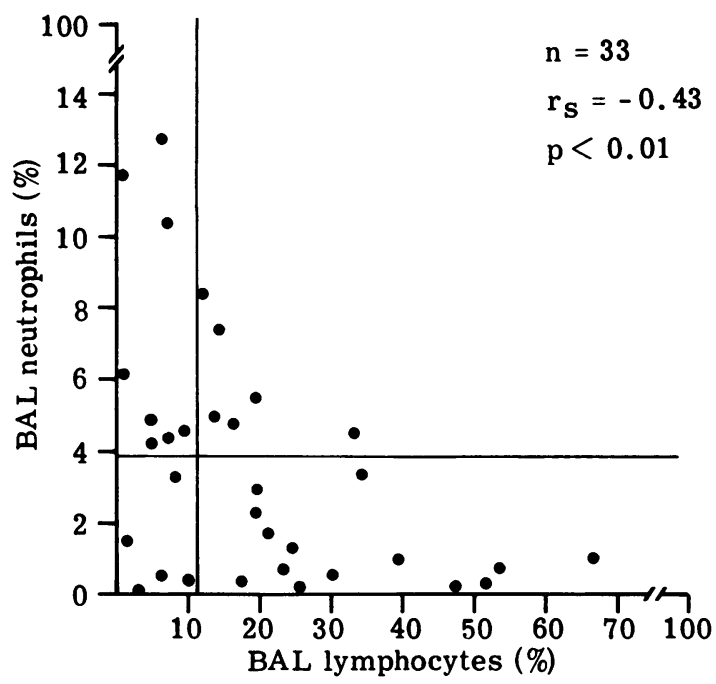

Fig 1 Relationship between percentages of bronchoalveolar lavage lymphocytes and neutrophils in 33 untreated patients with persisting sarcoidosis. The upper limits for our "normal" smoking populations, indicated by the vertical and horizontal lines respectively, are in accord with the values from many published series for normal smokers. 


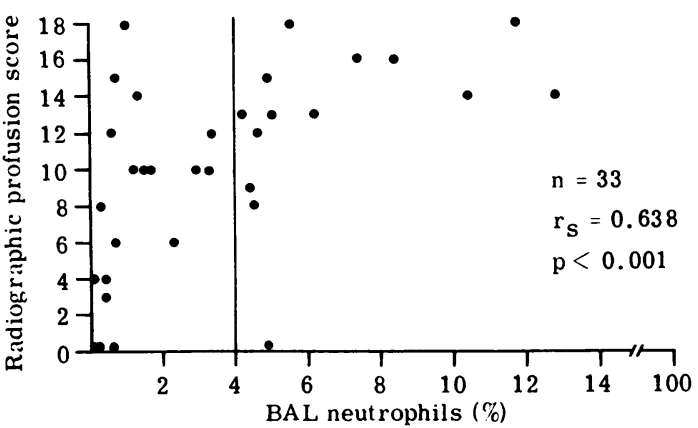

Fig 2 Relationship between the radiographic profusion scores and bronchoalveolar lavage neutrophil percentage counts.

The percentage of both lymphocytes and neutrophils showed significant differences between patients with and without evidence of contraction on the chest radiograph $(\mathrm{p}<0.03$ and $\mathrm{p}<0.001$ respectively) (fig 3 ). The median percentage of lymphocytes in patients without contraction was $20 \%$ compared with a median of $10.7 \%$ in those with contraction, while a higher pecentage of neutrophils was found in those with contraction (median 5.2\%) than in those without such a change (median $1.4 \%$ ).

CORRELATION BETWEEN LAVAGE CELL COUNTS AND RESULTS OF PULMONARY FUNCTION TESTS (table 3)

There was no significant correlation between the percentage of lavage fluid lymphocytes and vital capacity $(p<0.1>0.5)$ or TLCo. The percentage of lavage neutrophils, however, showed an inverse correlation with the vital capacity $(p<0.001$ ) (fig 4$)$, but an inverse correlation only at the $90 \%$ confidence limit $(p<0.1>0.5)$ with the TLCo. The relation between TLCO and vital capacity is shown in figure 5. This shows an overall correlation between TLCo and vital capacity with values of $85 \%$ predicted or greater in seven $(21 \%)$ and $19(58 \%)$ respectively. Both vital capacity and Tuco showed an inverse correlation with the profusion score of the chest radiographs $(\mathrm{p}<0.01$ and $\mathrm{p}<0.05$ respectively).

\section{OBSERVED DURATION OF DISEASE}

The estimated duration of disease as assessed from the known abnormal radiographs showed no correlation with lavage cell counts, profusion score on the chest radiograph, or results of pulmonary function tests.

\section{Discussion}

Our lung lavage results need to be considered in relation to the clinical state of our particular group of patients. Most of them (79\%) had persisting sarcoidosis (of at least one year's duration) and the need for treatment with corticosteroids was being assessed even though only four (12\%) patients had

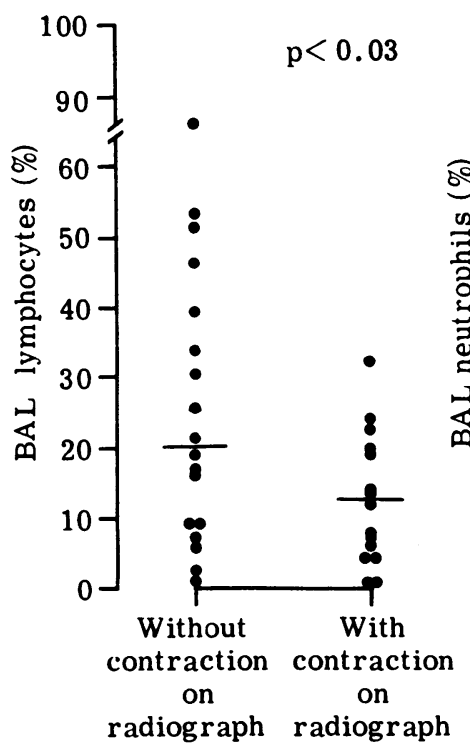

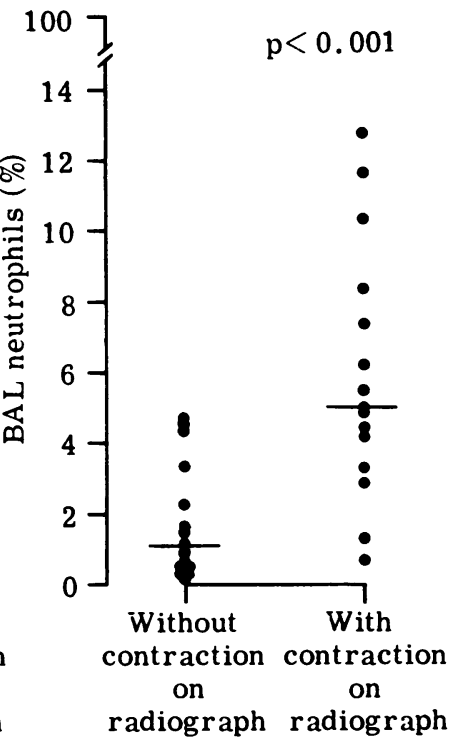

Fig 3 Distribution of bronchoalveolar lavage lymphocytes and neutrophils in those with and without radiographic evidence of contraction on the chest radiograph; medians are represented by horizontal bars. 
dyspnoea of more than grade 1.

Controversy continues about when corticosteroid treatment should be introduced for the treatment of pulmonary lesions. Some physicians wait for the development of respiratory symptoms; but in patients with persisting radiographic shadows but with only slight or no breathlessness or lung function abnormalities the assessment of "activity" of disease in the lung is of practical clinical importance, because it is at least logical to consider treatment if such radiographic abnormality persists. In our group only $24 \%$ had dyspnoea but $85 \%$ had abnormal cell counts of some type in lung lavage samples, including $23(88 \%)$ of the 26 patients with shadows that had persisted for more than a year. The frequency of

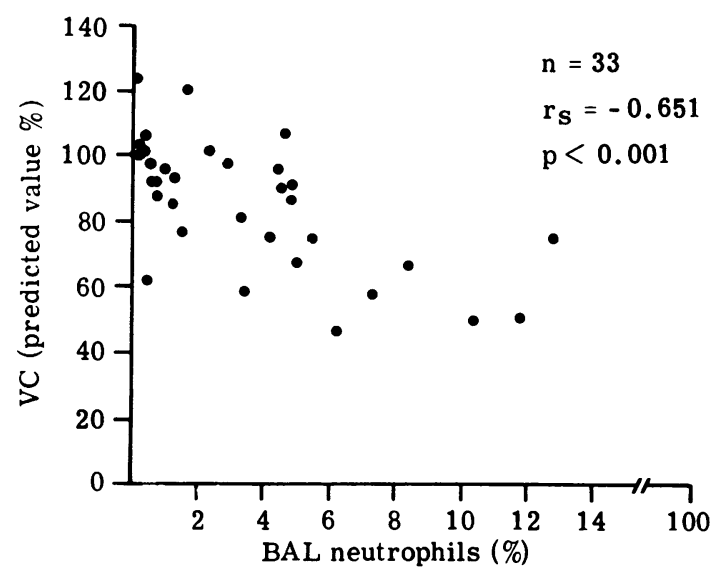

Fig 4 Relationship between the vital capacity (VC) and bronchoalveolar lavage neutrophils.

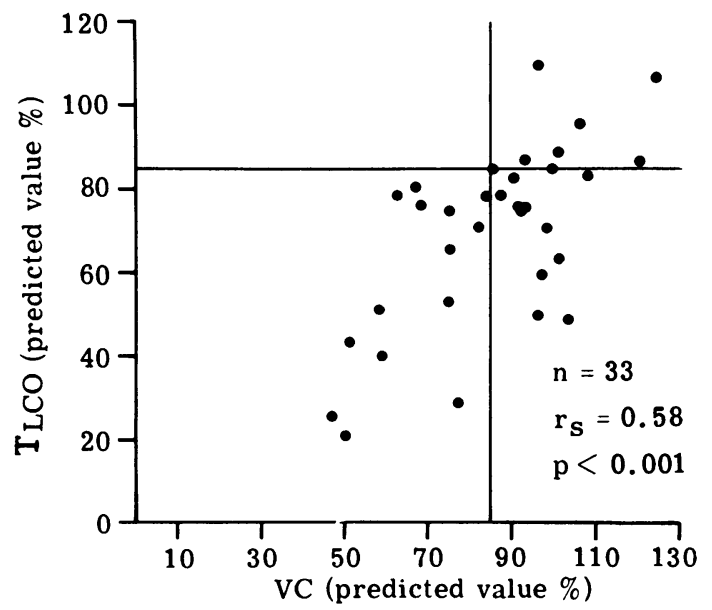

Fig 5 Relationship between values for vital capacity (VC) and carbon monoxide transfer factor (TLCO); $85 \%$ of predicted values is indicated by the vertical and horizontal lines respectively. increased lymphocyte counts for the group (61\%) is in accord with previous reports, although only eight cases $(24 \%)$ showed counts of over $28 \%$, falling roughly into the subgroup of "high intensity alveolitis" as defined by Hunninghake and his colleagues.' Because we have used total lymphocyte rather than $T$ cell counts the numbers in our study with high intensity alveolitis on the basis of Hunninghake's precise criteria would be even lower. The frequency and extent of increase of lymphocytes has been shown to vary with the radiographic stage of disease. The influence of other factors such as race also needs to be determined, since this may make series of patients in North America and Europe difficult to compare. Technical differences in the preparation and staining of cells for counting, as well as subjective variation between different observers, may also account for some variability in reports from different laboratories.

Fewer investigators, however, have reported an increase in bronchoalveolar lavage neutrophils in patients with sarcoidosis. ${ }^{271314}$ Yeagar and his colleagues $^{2}$ showed that the mean percentage of lavage neutrophils was $0.9 \%$ in 10 non-smokers and $7.2 \%$ in four smokers with sarcoidosis. Several years ago Reynolds $^{13}$ also reported a slight increase in lavage neutrophils $(6.6 \%$ (SD $1.5 \%)$ ) in a series of 16 cases. Roth et $\mathrm{l}^{14}$ showed a significantly higher percentage of neutrophils in 14 patients with "advanced" sarcoidosis with fibrosis (8\% (SD11\%)) than in 80 patients with earlier stages of disease $(1 \%$ $(2 \%))$. Our study not only confirms our earlier report $^{7}$ of a trend of increase of neutrophils with radiographic contraction but also shows a correlation with the overall radiographic profusion score $(p<0.001)$. It is therefore reasonable to infer that lavage neutrophils may reflect the severity of the parenchymal lesions as well as the presence of fibrotic distortion of the lung.

Crystal and his colleagues ${ }^{5}$ have reported that patients with more than $28 \%$ of $\mathrm{T}$ lymphocytes in lung lavage fluid have a greater deterioration in their lung function when followed over six months without treatment than do those with lower lymphocyte counts. This evidence has been used to suggest that high concentrations of lavage lymphocytes may be used to indicate a need to introduce corticosteroid treatment. But about $70 \%$ of patients with early lung infiltrates (many of whom are now known to have substantial lymphocyte counts) subsequently undergo spontaneous radiographic remission within about two years. ${ }^{15} 16$ Thus "activity" defined simply as transient radiographic, physiological, or symptomatic deterioration over a few months does not, in the view of many physicians, necessarily imply an obligatory need for immediate therapeutic interven- 
tion. The longer term natural history of patients with early disease and raised lymphocyte counts has not yet been reported in any detail, and until this is known the importance of the lymphocyte count as an indicator for starting treatment must remain undecided.

The important question is how to define and determine "activity" in patients with persisting abnormal radiographs, whose lesions are less likely to resolve spontaneously and are more likely to progress to fibrosis. In an earlier report we showed that in addition to lymphocytes many lavage constituents are increased in more chronic sarcoidosis, including neutrophils, $\beta_{2}$ microglobulin, albumin, and histamine.? Our studies, however, have shown that while the lymphocyte percentage counts are also often increased above normal, few patients have "high intensity alveolitis." Does this imply that the disease is less active or that lymphocyte counts are of less value in monitoring "activity" in patients with persisting disease? The results of corticosteroid treatment in the group of patients reported here and the subsequent changes in lavage cell counts will be published in detail separately, but overall $80 \%$ of them showed a substantial radiographic improvement. ${ }^{7}$ To deny these patients treatment on the basis of their frequently low lymphocyte counts would not therefore seem appropriate if radiographic clearing is the selected objective.

There are many other unanswered questions. What is the role of neutrophils in the pathogenesis of more persisting sarcoidosis? In particular, are they the consequence of distorted lung architecture, does their recruitment limit collagen accumulation, or do they promote further tissue damage?

Whatever the answers to these more fundamental questions, we suggest that both abnormal lymphocyte and abnormal neutrophil counts are important in the assessment of patients with persisting sarcoidosis, and that neutrophil counts relate to the radiographic profusion score, the presence of contraction, and abnormal lung function more closely than do lymphocyte counts.

One of us (YHL) was supported on sabbatical leave by a scholarship from Sandoz, to which we are grateful for this opportunity. Laboratory support for the bronchoalveolar lavage studies has been provided by the Tobacco Advisory Council and the Chest, Heart, and Stroke Association; and we acknowledge Mrs Zoe Primett, Mr David Hughes, and Mr Philip Townsend for their help in preparing the samples.

\section{References}

1 Hunninghake GW, Gadek JE, Kawanami O, Ferrans VJ, Crystal RG. Inflammatory and immune processes in the human lung in health and disease: evaluation by bronchoalveolar lavage. Am J Pathol 1979;97:149206.

2 Yeager $\mathrm{H}$ jun, Williams MC, Beekman JF. Sarcoidosis: analysis of cells obtained by bronchial lavage. Am Rev Respir Dis 1977;116:951-5.

3 Arnoux A, Morcamp C, Tonnel AB, et al. Bronchopulmonary cellular and protein studies in sarcoidosis and hypersensitivity pneomonitis. In: Williams WJ, Davies $\mathrm{BH}$, eds. Proceedings of the Eighth International Conference on Sarcoidosis and Other Granulomatous Disorders. Cardiff: Alpha Omega Publishing, 1980:409-16.

4 Perrim-Fayolle M, Biot N, Harf R, Chevalier JP, Frobert E, Brun J. Studies on bronchoalveolar lavage in sarcoidosis: total proteins, immunoglobulins, alpha-antitrypsin, transferrin and complement fractions. In: Williams WJ, Davies BH, eds. Proceedings of the Eighth International Conference on Sarcoidosis and Other Granulomatous Disorders. Cardiff: Alpha Omega Publishing 1980:402-8.

5 Crystal RG, Roberts WC, Hunninghake GW, Gadek JE, Fulmer JD, Line BR. Pulmonary sarcoidosis: a disease characterized and perpetuated by activated lung T-lymphocytes. Ann Intern Med 1981;94:73-94.

6 UICC Committee. Cincinnati classification of the radiographic appearances of pneumoconioses: a cooperative study. Chest 1970;58:57-67.

7 Haslam PL, Coutts II, Watling AF, et al. Bronchoalveolar lavage features associated with radiographic evidence of fibrosis in pulmonary sarcoidosis. In: Chrétien J, Marsac J, Saltiel JC, eds. Proceedings of the Ninth International Conference on Sarcoidosis and Other Granulomatous Disorders. Paris: Pergamon Press, 1983:209-15.

8 Medical Research Council Committee on Research into Chronic Bronchitis. Instructions for the use of the questionnaire on respiratory symptoms. London: Medical Research Council, 1966.

9 Rudd RM, Haslam PL, Turner-Warwick M. Cryptogenic fibrosing alveolitis: relationships of pulmonary physiology and bronchoalveolar lavage to response to treatment and prognosis. Am Rev Respir Dis 1981;124:1-8.

10 Cotes JE. Lung function: assessment and application in medicine. 3rd ed. Oxford: Blackwell, 1975.

11 Haslam PL, Turton CWG, Lukoszek A, Salsbury AJ, Turner-Warwick M. Bronchoalveolar lavage fluid cell counts in cryptogenic fibrosing alveolitis and their relation to therapy. Thorax $1980 ; 35: 328-39$.

12 Reynolds HY, Newball HH. Analysis of proteins and respiratory cells obtained from human lungs by bronchial lavage. J Lab Clin Med 1974;84:559-73.

13 Reynolds HY. The importance of lymphocytes in pulmonary health and disease. Lung 1978;155:225-42.

14 Roth C, Huchon GJ, Arnoux A, Stanis las-Leguern G, Marsac JH, Chrétien J. Bronchoalveolar cells in advanced pulmonary sarcoidosis. Am Rev Respir Dis $1981 ; 124: 9-12$.

15 Scadding JG. Sarcoidosis. London: Eyre and Spottiswoode, 1967:97-173.

16 Middleton WG, Douglas AC. Prolonged corticosteroid therapy in pulmonary sarcoidosis. In: Williams WJ, Davies BH, eds. Proceedings of the Eighth International Conference on Sarcoidosis and Other Granulomatous Disorders. Cardiff: Alpha Omega Publishing, 1980:632-47. 